\title{
Dynamic simulations of excavations with yielding bolts
}

\author{
C.R. Lilley Beck Engineering Pty Ltd, Australia \\ T. Roberts Jennmar Australia Pty Ltd, Australia \\ G. Putzar Beck Engineering Pty Ltd, Germany \\ D.A. Beck Beck Engineering Pty Ltd, Australia
}

\begin{abstract}
We describe $3 D$ simulations of rockbolts installed in a tunnel intersection geometry in a jointed rock mass subjected to an extreme dynamic loading event. A newly developed yielding rockbolt was simulated, using a bolt model calibrated from laboratory drop tests. The results show that most of these yielding bolts can still retain load carrying capacity even with up to $1 \mathrm{~m}$ of closure, for the simulated conditions. The same dynamic simulation using fully encapsulated resin grouted rockbolts indicated that a significant fraction of resin bolts fail at $100 \mathrm{~mm}$ of closure. The simulations demonstrate several important components of a framework for realistic simulations of excavations and ground support systems subjected to dynamic loading. Many parts of this framework are proposed as technology development directions, and combining all parts into workable simulations will indeed be challenging. However, for critical excavations, such sophisticated analyses may be justified.
\end{abstract}

\section{Introduction}

Mining where high deformation is expected necessitates a ground support system that can reliably maintain its integrity at the expected deformation levels. Such deformation can occur quasi-statically, which is often called squeezing conditions, or dynamically, as it occurs in rockbursting conditions. The dynamic component of deformation is of most concern when designing a ground support system, since it effectively occurs instantaneously and offers no opportunity to monitor and respond to the deformation as it develops.

Many rockbolts have been designed over the years to fulfil the requirement for high deformation capacity, and these are often called yielding rockbolts. Such bolts incorporate design features that permit deformation without bolt failure using a variety of mechanisms (see Potvin et al., 2010). The Yield-Lok bolt, developed by John Oldsen of Jennmar (Wu and Oldsen, 2010) is one recently developed yielding rockbolt.

This paper describes simulations that were conducted to characterise the response of Yield-Lok bolts under dynamic loading conditions. This response has been compared to that of typical fully encapsulated resin bolts, which are often used for reinforcement but which have less deformation capacity.

The simulations utilise several components of a developing framework for dynamic simulations of excavations. This framework, described at the end of the paper, is proposed for critical excavations where dynamic loading poses significant risks, and also maps out several technology development directions for achieving realistic simulations of excavations and ground support systems under dynamic loading.

\section{$2 \quad$ Yield-Lok description and drop test results}

The Yield-Lok rockbolt shown in Figure 1 is engineered to yield at a defined load, with further post-yield deformation at an almost constant load. The post-yield load carrying capacity provides on-going rock mass reinforcement under high deformation static and dynamic loading conditions. The bolt consists of a smooth solid bar and an engineered anchor system, comprising a polymer sleeve and an upset at the end of the bar, which is the key feature of the bolt. The upset and polymer sleeve are engineered so that the upset 
pulls through the polymer at an almost constant load, which is designed to be slightly less than the yield load of the bar. The anchor absorbs energy during yield by deforming the polymer sleeve, and current production bolts allow for up to $700 \mathrm{~mm}$ of anchor yield which is a substantial deformation capacity relative to other yielding reinforcement systems (see Potvin et al., 2010). An important feature of the Yield-Lok bolt is that it can be installed with standard resin capsules and bolting equipment, so it can be used as primary support in the normal development cycle. It can therefore provide dynamic reinforcement capacity at the development face, without the need for a second bolting pass as it the case for some other yielding rockbolts.

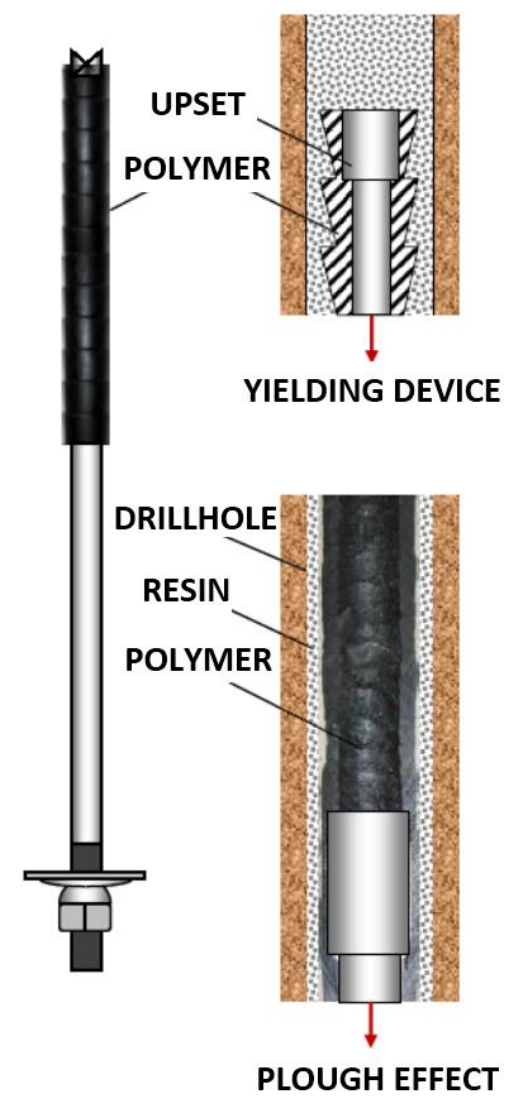

Figure 1 Details of Yield-Lok bolt (Jennmar, 2012)

Drop tests have been conducted for Jennmar at CANMET's laboratory in Ottawa (Plouffe et al., 2008) to quantify Yield-Lok performance under controlled axial loading conditions. In these tests, the bolts were installed inside steel pipes, suspended from a testing frame and subjected to an impulsive load by dropping a mass onto the plate. During the tests, histories of loads on the plate and the testing frame, and the displacement, were recorded. Figure 2 shows some typical drop test results. 

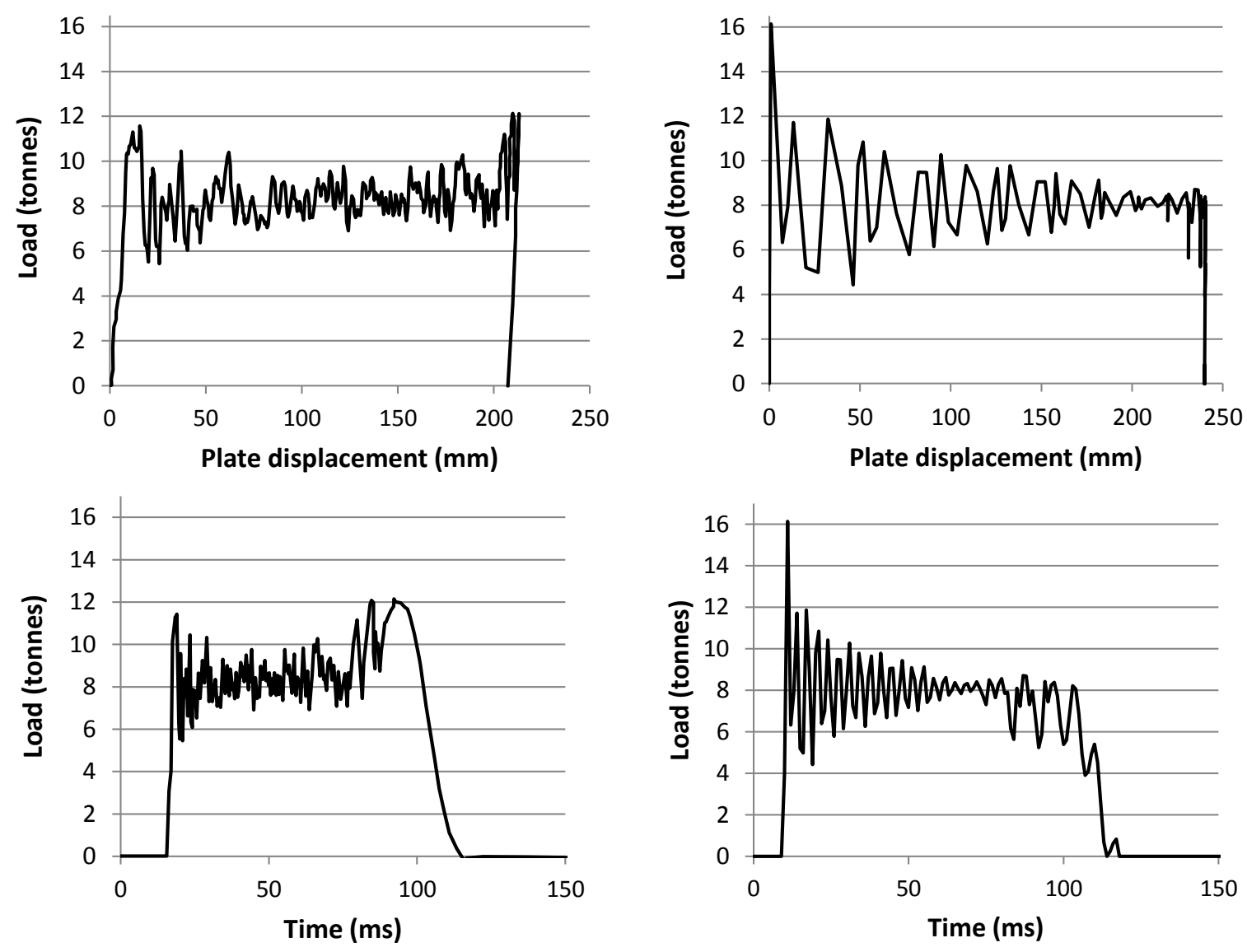

(a) Drop test data (test Jen-45 drop 1)

(b) Modelled Yield-Lok response

Figure 2 Typical Yield-Lok drop testing results compared to calibrated model response. This test involved a $1,115 \mathrm{~kg}$ mass dropped from a height of $1.5 \mathrm{~m}$, giving $16.4 \mathrm{~kJ}$ of kinetic energy absorption per test

The typical drop test response was:

- An initial yield load of $\sim 12$ tonnes. This is thought to be related to the early strength of the polymer sleeve, before work on the anchor mechanism causes high local heating rates and changes in the polymer materials leading to the lower longer term yield load of 8 tonnes.

- A yield distance of $200 \mathrm{~mm}$.

- A yield period of $\sim 100 \mathrm{~ms}$.

These are approximate averages for the CANMET testing programme, but individual results vary from test to test by $\sim 20 \%$. Later testing for Jennmar at CANMET showed variations with different hole diameters, resin types and different upset geometries, but the typical response given above is a suitable benchmark for this demonstration, since the main features of the Yield-Lok bolt response have been captured.

Some bolts in the CANMET testing programme were subjected to repeated drop tests, resulting in a further $200 \mathrm{~mm}$ to $250 \mathrm{~mm}$ of yield for the same energy absorption, showing that the Yield-Lok bolt can sustain deformation over the full length of the yielding anchor device without a significant change in the yielding behaviour. The bolts can yield over the full length of the anchor, which is $700 \mathrm{~mm}$ in current production bolts, plus additional yield thereafter as the upset engages and pulls through the resin, although this latestage aspect of bolt performance has not yet been investigated. 


\section{Yield-Lok model formulation and calibration}

The Yield-Lok bolts were modelled as assemblies of shear flexible Timoshenko beam elements (Dassault Systèmes, 2013). The beams were connected to the surrounding material in a complex way using embedded elements to capture the 3D deformation of bolt hole when simulated in a deformed rock mass.

In this demonstration, only the translational degrees of freedom were connected to the surrounding material. The nodal displacement components perpendicular to the bolt axis are tied to the surrounding material at all times after bolt installation. Displacement along the bolt axis is possible, providing a capacity to capture slip. Sliding nodes received a frictional force according to the position along the bolt and which also depends on the state of degradation of the bolt bonding at that position. This frictional setup allows the required yielding anchor characteristics of the Yield-Lok to be captured. The bolt collar is constrained to move in one direction to capture the effect of the plate. Possible plate failure can be captured by choosing appropriate properties of the first beam element. More sophisticated connection arrangements are possible and are a subject of on-going technical development.

The typical bolt behaviour from the drop tests as described above was used to set model parameters for the simulated Yield-Lok bolts. Before incorporating these Yield-Lok bolts in simulations of underground excavations, the bolt was tested numerically in a simulated drop testing arrangement to demonstrate that the modelled bolt can indeed represent the drop tests with sufficient similitude. Figure 3 shows the modelled calibration setup and the resulting modelled bolt response is shown in Figure 2 for direct comparison with the example test results. The modelled bolt captures the main features of the Yield-Lok drop tests: Peak load at 14 to 16 tonnes, longer term slip load at 8 tonnes, a slip distance of $200 \mathrm{~mm}$ and yield time of $\sim 100 \mathrm{~ms}$ for the simulated drop test. There are some differences, as apparent in Figure 2, but the main features of the Yield-Lok response have been captured by the model.

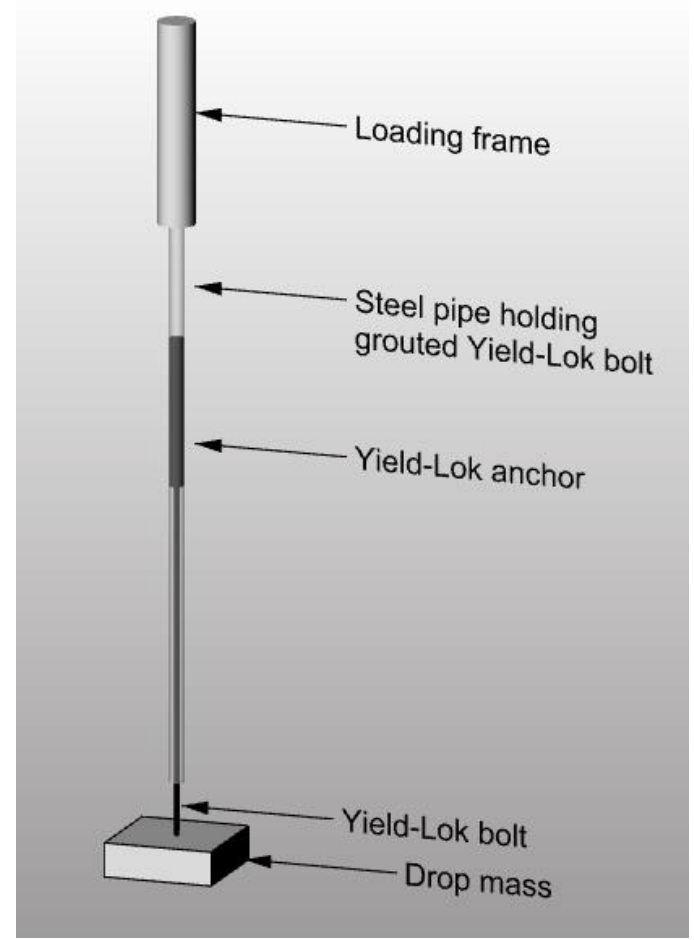

Figure 3 Model setup for dynamic calibration of Yield-Lok model element (not to scale)

\section{$4 \quad$ Dynamic simulations}

To characterise Yield-Lok behaviour in a realistic loading scenario, the bolts were simulated in an underground tunnel intersection in a jointed rock mass, as shown in Figure 4. This simulation used a 3D 
discontinuum finite element modelling framework incorporating a strain-softening dilatant material model between the joints that were explicitly modelled (Levkovitch et al., 2010).

Realistic simulations of bolt behaviour depend on the behaviour of structures down to the scale of the bolt spacing, approximately, because structurally bounded block movements at this scale and larger dominate bolt deformation. It is therefore essential to capture these structures in a rockbolt simulation, and this is the motivation for the 3D discontinuum modelling approach applied here. Ignoring or downplaying structural effects in a rockbolt simulation is unlikely to provide realistic results. The scale requirements mean that structures on a $\sim 1 \mathrm{~m}$ scale need to be modelled, necessitating many structures for a model containing realistic excavation geometry. With current technology, the practical limit is several hundred structures in 3D dynamic simulations, but this will certainly grow with further technology improvements.

For this demonstration, three joints sets were modelled, to represent a blocky rock mass with persistent structures, as well as several randomly oriented joints. The structures were simulated explicitly with cohesive finite elements with yield characteristics set using a generalised Hoek-Brown yield model (Levkovitch et al., 2010), although any required constitutive model can be applied to the cohesive elements (Levkovitch et al., 2010). Figure 4 shows the modelled joints. The continuum rock mass properties, between the explicit structures, were selected to represent a strong igneous rock mass characteristic of granodiorite.

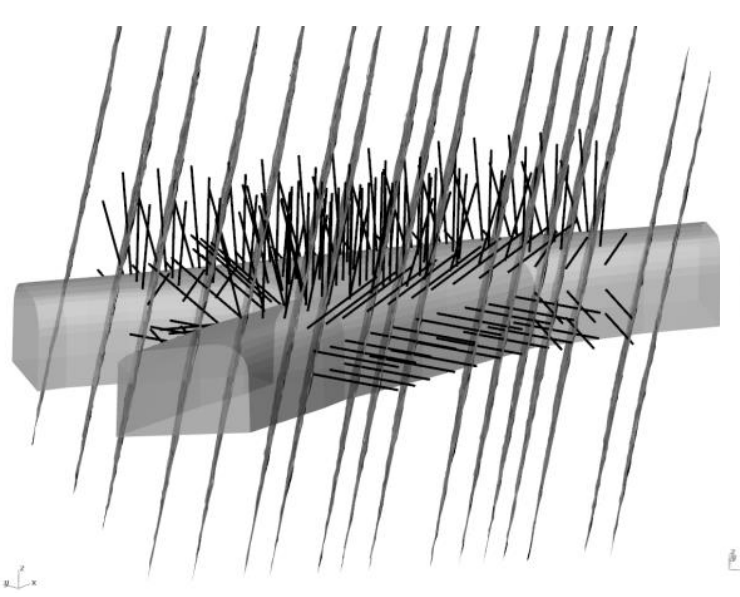

Joint set 1

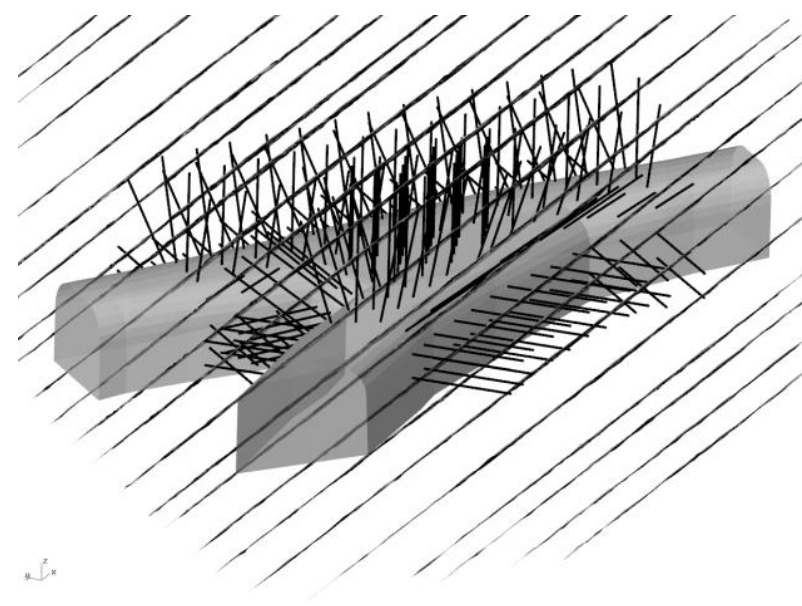

Joint set 3

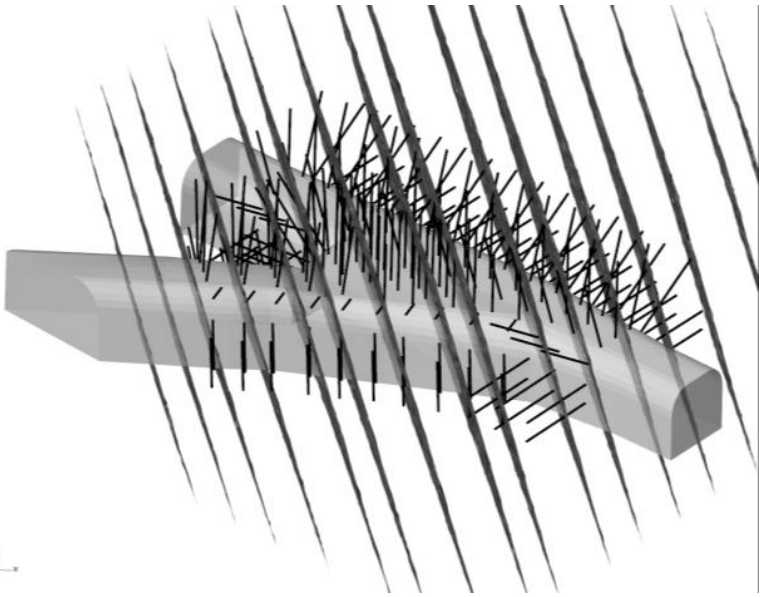

Joint set 2

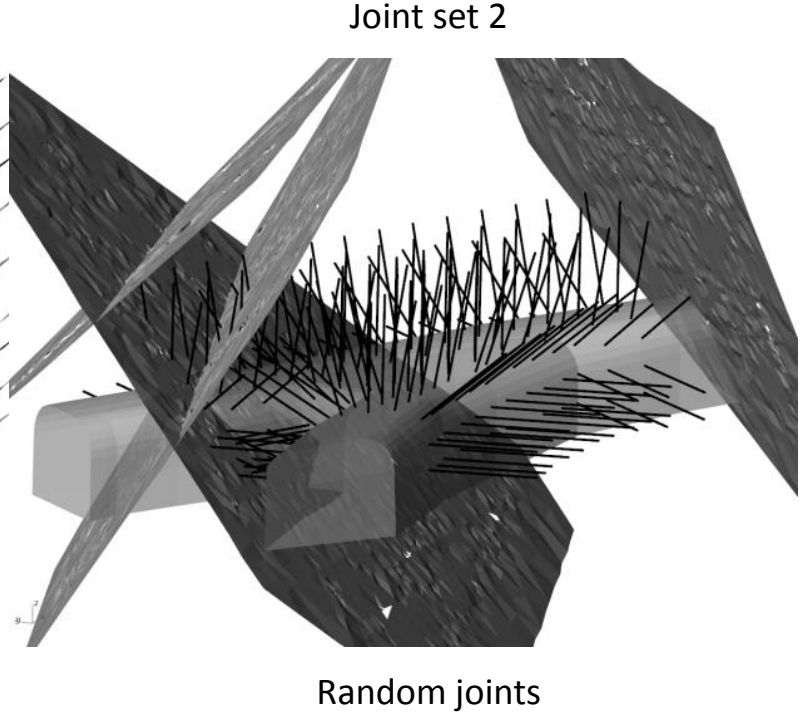

Figure 4 Oblique views showing simulated intersection geometry with yielding bolts and the explicitly modelled structures. The bolts are $2.4 \mathrm{~m}$ long, and 194 were modelled. The nominal development profile is $5 \mathrm{~mW} \times 5 \mathrm{mH}$ leading to the intersection 
Simulation results were recorded at 122 time points to achieve high temporal resolution. The simulation comprised an initial quasi-static phase during tunnel excavation, followed by two rapid loading events intended to represent an extreme example of dynamic loading in response to, for example, nearby pillar collapses that could occur in a stoping operation under high stress conditions. The dynamic loading condition was generated by imposing two rapid shearing events on the model boundaries. These events were applied over $200 \mathrm{~ms}$ at 50 and $75 \mathrm{~mm} / \mathrm{m}$.

The model contained $680 \times 10^{3}$ higher-order tetrahedral volume elements, $870 \times 10^{3}$ cohesive elements, and 2,500 elements associated with the Yield-Lok bolts. The bolt assembly additionally requires a considerable number of mutable constraints.

\subsection{Excavation response}

The intersection deformation history is reported here in terms of closure between pairs of points, which represent closure measurements that might be conducted in practice. Figure 5 shows these closure measuring stations for the simulated excavation. 4D visualisation of deformation (3D plus time) is required to fully appreciate the large amount of data contained in the simulation results database, so only snapshots can be provided here.
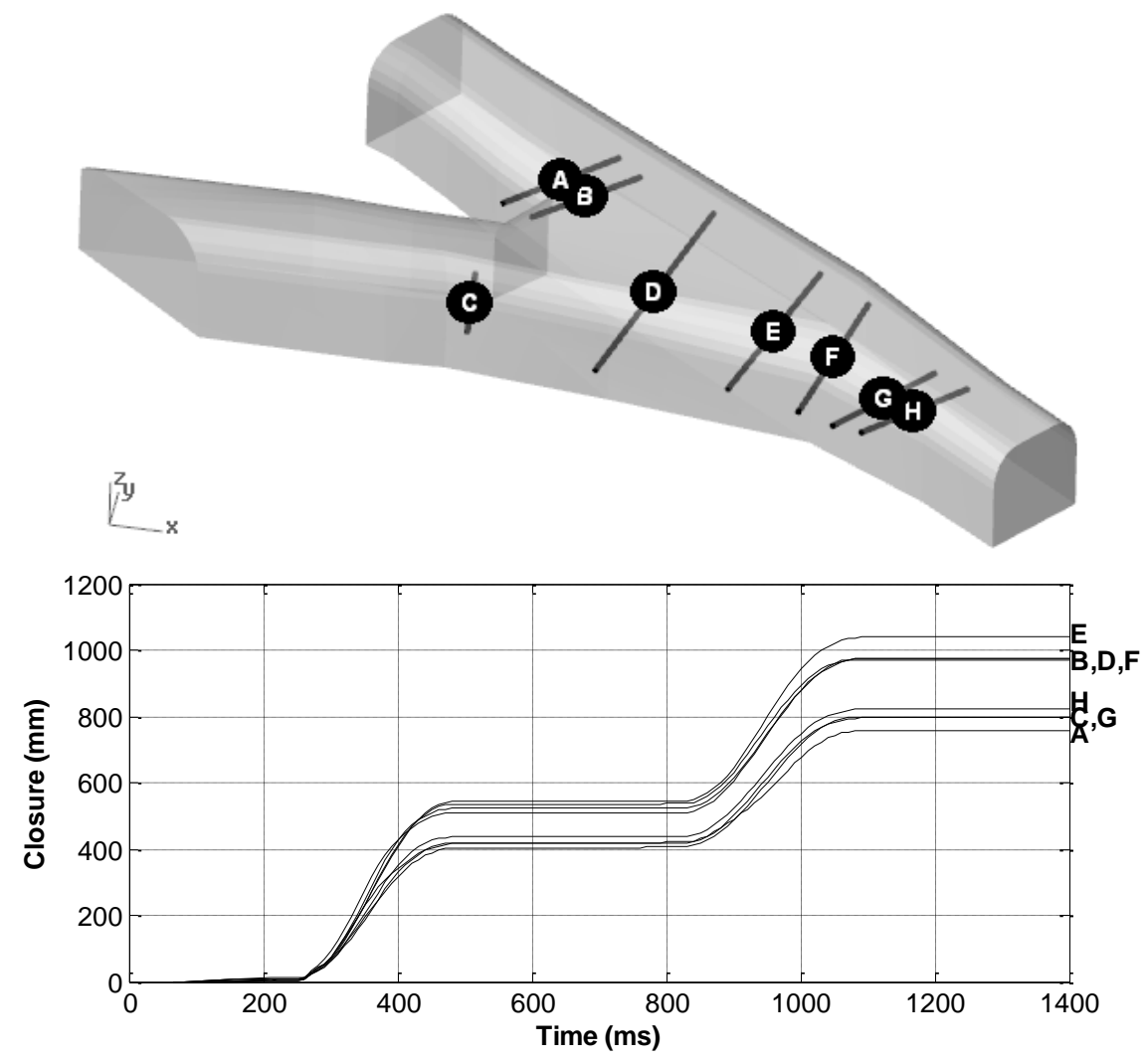

Figure 5 Closure history for intersection simulation with Yield-Lok bolts installed. Closure was reported for the lines between wall nodes as shown in the oblique view of the intersection

The velocity and speed recorded at a selected wall node are plotted in Figure 6 . 

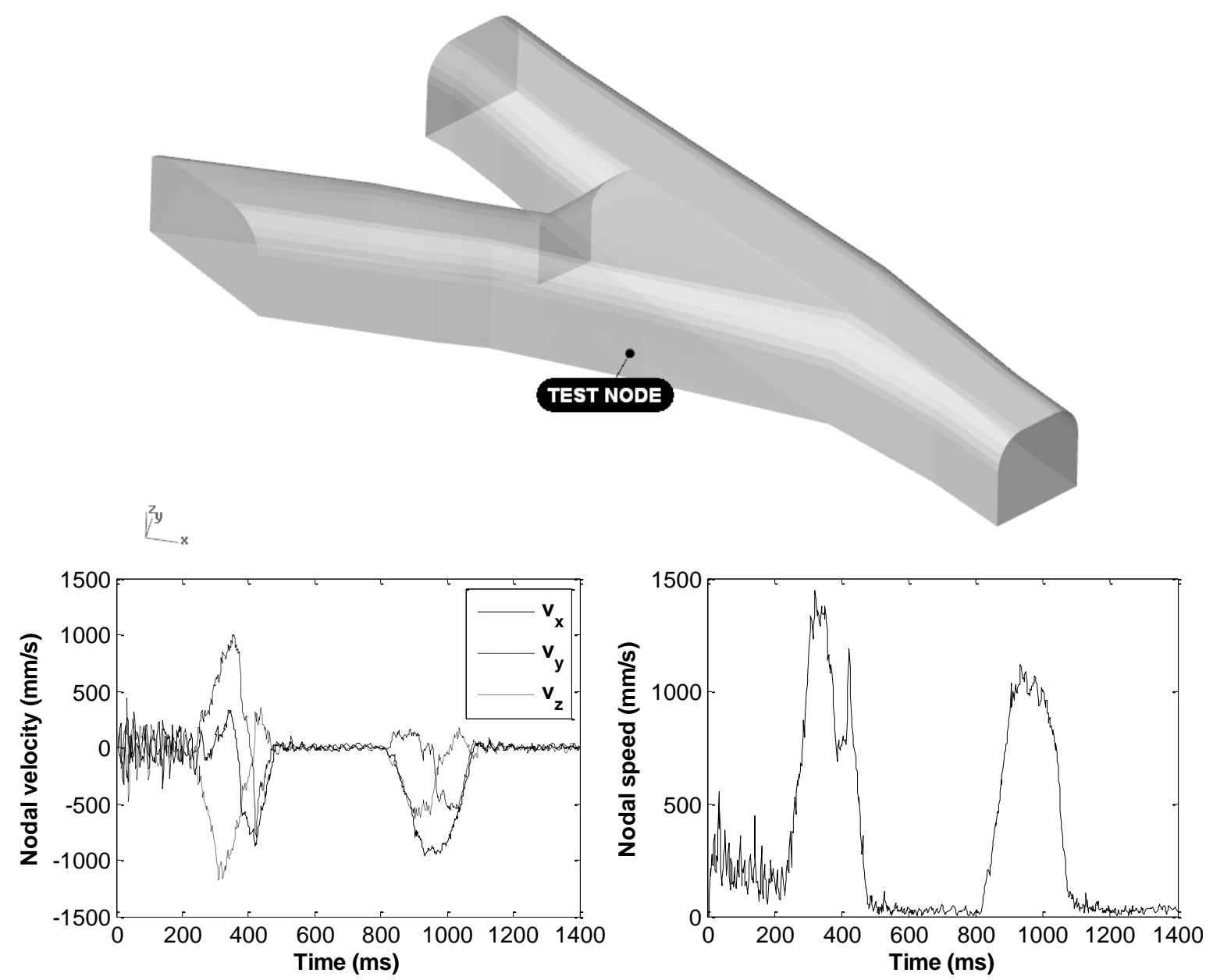

Figure 6 Histories of nodal velocity components and nodal speed (ppv). The nodal speed is the magnitude of the nodal velocity vector

As shown in Figure 6, nodal speeds well over $1,000 \mathrm{~mm} / \mathrm{s}$ were realised in the simulation which exceed the damage thresholds based on typical ppv scales. The velocity history shown in Figure 6 does not show $P$ and $S$ wave signatures because these are observed in the far field, away from the seismic event, while this simulation is being performed in the near field within the rapidly deforming rock mass.

\subsection{Yielding bolt response}

Figure 7 shows the load response for all 194 bolts over the entire simulation, and the image in Figure 8 illustrates bolt deformation and rock mass damage during the simulation. It shows the bolts yielding at an initial load of $\sim 12$ tonnes, with longer term slip at $\sim 8$ tonnes.

The simulation indicates that the Yield-Lok bolts do not fail under these extreme conditions, and even with $\sim 1,000 \mathrm{~mm}$ of closure, only two bolts yield through the full length of the anchor mechanism. 

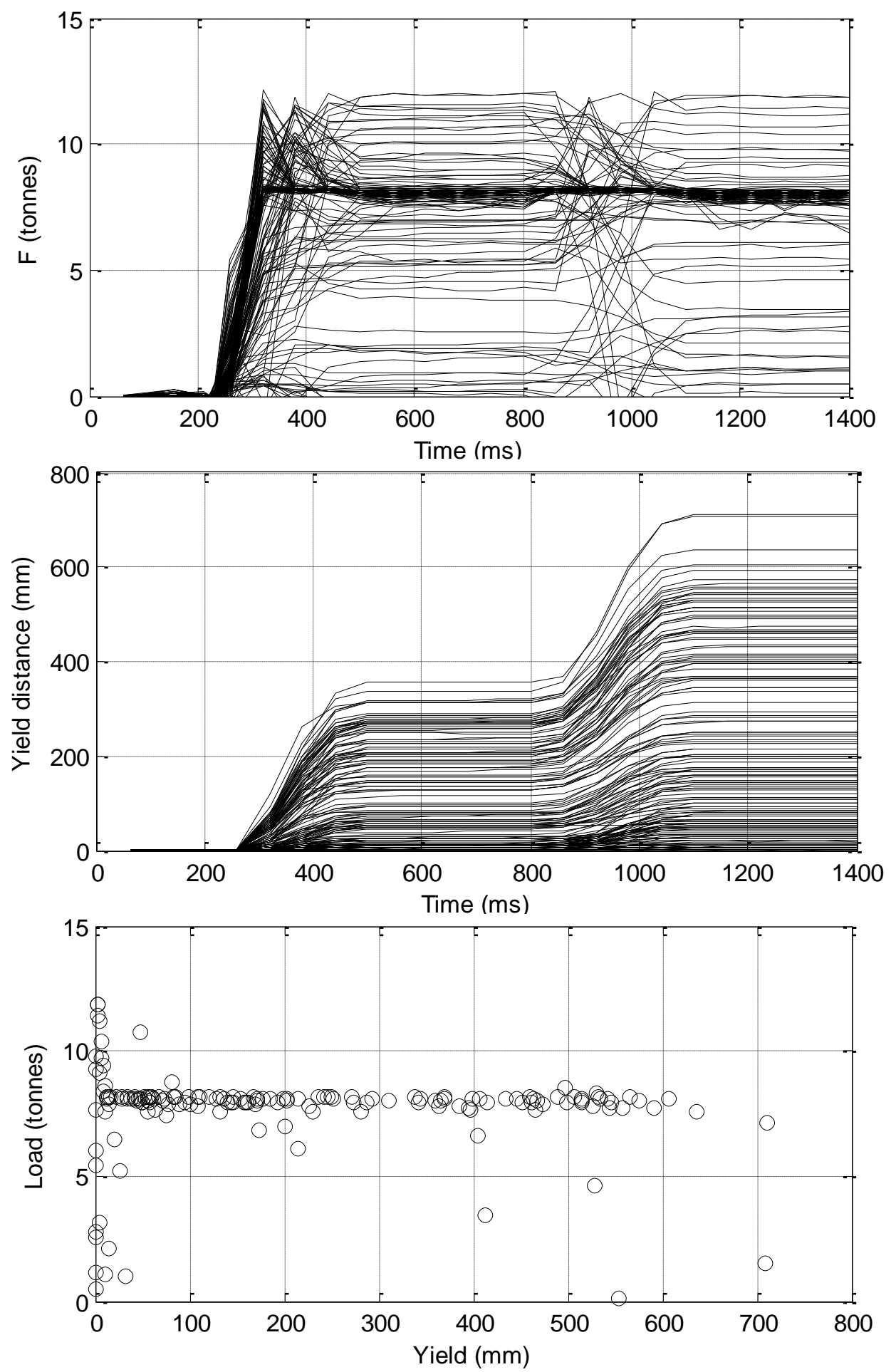

Figure 7 Load and yield behaviour for all 194 simulated Yield-Lok bolts. The load versus yield plot is for the end of the simulation 


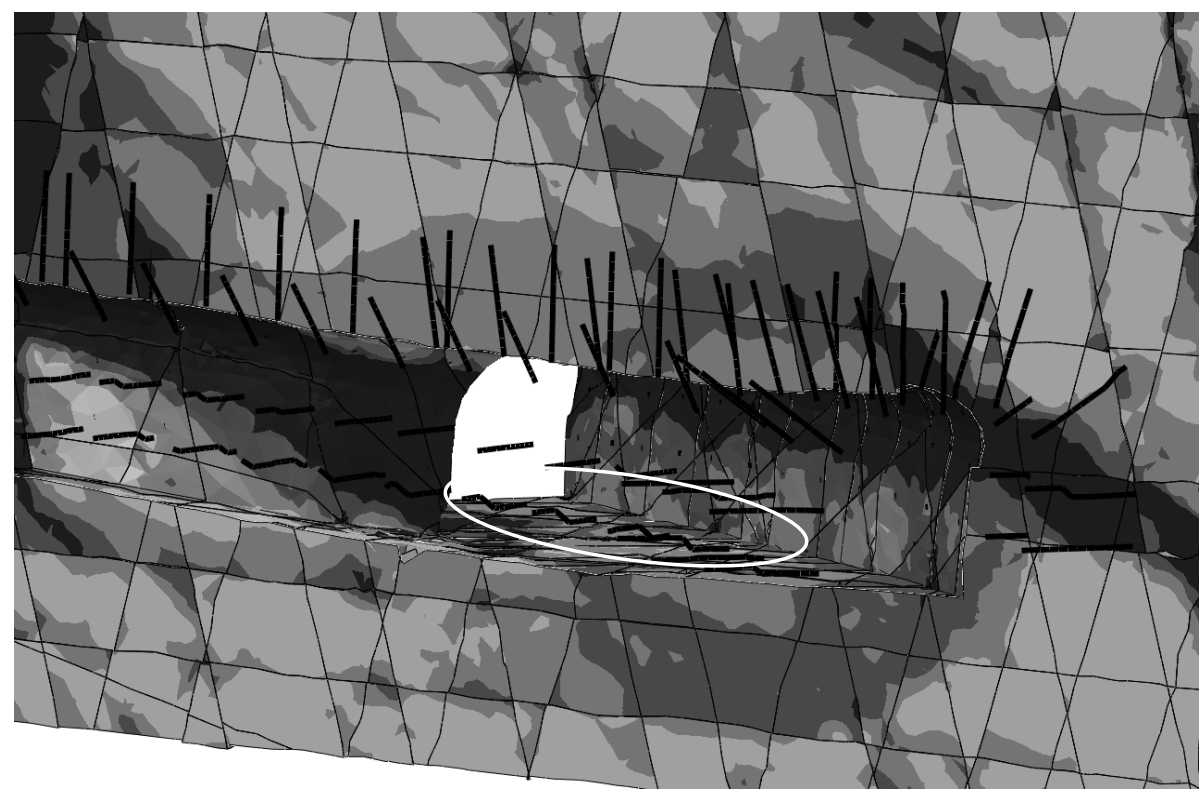

Figure 8 Vertical cross-section through model at $\sim 800 \mathrm{~ms}$ showing plastic strain, interpreted as rock mass damage, and bolt deformation. Some examples of bolts undergoing shear across structures are indicated. In this image joints are shown as black lines, and darker shading indicates higher levels of rock mass damage

As shown in Figure 8, the simulation captures shear deformation in the bolts arising from dislocation on structures. Shear response of the Yield-Lok bolts is not explicitly captured by the constitutive formulation in this simulation, and indeed this is a direction for further investigations into Yield-Lok behaviour and rockbolts in general. Given the smooth bar, our expectation would be that these bolts could sustain more shear deformation than deformed bars, but this would of course need to be confirmed with testing.

\subsection{Comparison with resin bolts}

To compare the response of fully encapsulated resin bolts with the Yield-Lok bolts, the same simulation as described above was run with resin bolts installed instead of Yield-Lok bolts. Closure recorded during this simulation and the fraction of failed resin bolts are plotted in Figure 9. When comparing with the closure for the yielding bolts in Figure 5 is apparent that the response, in terms of excavation closure, is very similar for both simulations. This is because the applied deformation, in this case, dominates the excavation behaviour and the resistance to deformation offered by the reinforcement system has a comparatively small impact.

Figure 9 also shows the number of resin bolts that exceed the modelled strain limit which was set at $12 \%$ over $100 \mathrm{~mm}$ for this simulation. Even at a modest deformation level, characterised by closure of $\sim 100 \mathrm{~mm}$, more than $30 \%$ of the resin bolts exceed this strain limit, showing that a significant fraction will fail. This behaviour is observed in practice, where resin bolts are often observed to fail under high deformation (Potvin et al., 2010), hence the motivation for developing yielding reinforcement systems. 

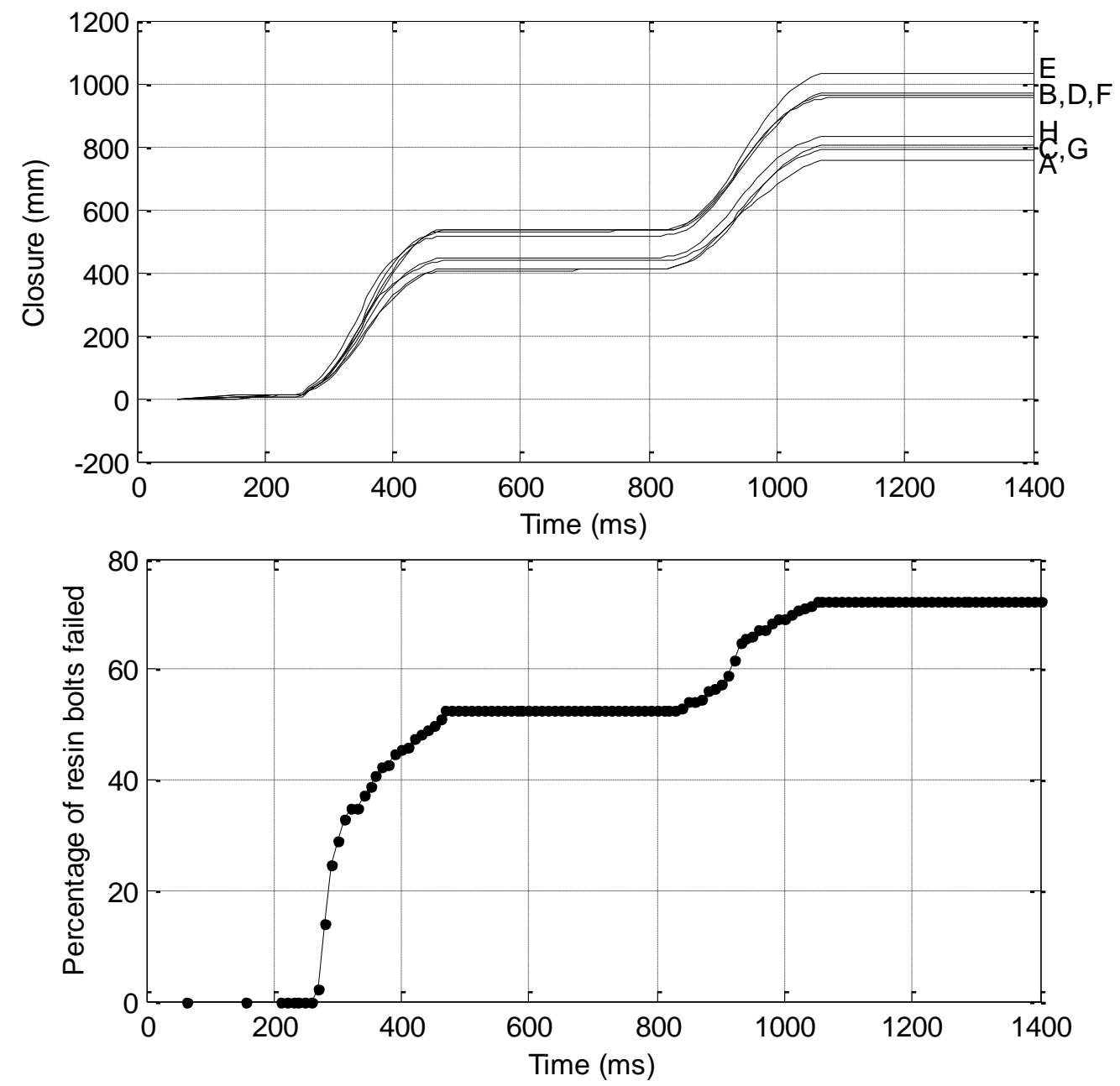

Figure 9 Time histories of closure and percentage of failed bolts for dynamic simulation with resin bolts installed. Closure is reported for the same locations as shown in Figure 6

\section{$5 \quad$ Discussion on modelling results}

The modelling work reported here was intended to characterise the performance of a specific yielding rockbolt under an extreme dynamic loading scenario. The results show that the yielding bolts, as implemented in the model, can survive high levels of deformation. This compares to fully encapsulated resin grouted bolts where at even modest deformation levels of $\sim 100 \mathrm{~mm}$, over $30 \%$ of the bolts fail. Even though an extreme dynamic loading case was modelled here, the results do demonstrate that Yield-Lok bolts may offer more capability for maintaining near-field excavation stability, since they still retain 8 tonnes of load carrying capacity after yield.

Since this work focussed on the performance of rockbolt reinforcement the surface support, which is the other main component of the overall ground support system, has not been considered in detail. As is well known in mining practice, the weak link in the overall ground support system will certainly still be the surface support arrangement and this is well documented by, for example, Potvin et al. (2010) and citations therein. Where high deformation levels are expected, be they quasi-static or dynamic, the surface support design is critical. For high deformation the surface support typically comprises fibrecrete, mesh and straps, all tied together with the deep reinforcement. Standing support, such as timber poles, yielding props and steel sets are also used in some circumstances. The comparatively low deformation capacity of fibrecrete (Potvin et al., 2010) means that it should only be used in combination with steel mesh and straps which can survive much higher deformation levels, and should not wholly replace it. 
Large spans, such as the intersection geometry simulated here, still need longer reinforcement elements, and rockbolts cannot usually fulfil this requirement. Cable bolts, perhaps with a designed dynamic capability, will likely continue in this role but yielding bolts still fulfil an important intermediate length reinforcement function in large spans. The capability to install Yield-Lok bolts with a jumbo in the normal development cycle means that they provide primary reinforcement with dynamic capacity at the working face, before cable bolts are installed and plated.

There are two aspects of the simulation framework and the current Yield-Lok design that suggest a need for further development. Firstly, as the results show, the bolts show a significant shearing component across structures as would be expected, but as far as we are aware, there has been no research into the dynamic shear behaviour of rockbolts. Dynamic shear testing is required to improve the understanding of this behaviour and this poses a challenging research question. Initial studies are underway to address this.

The second aspect is the energy absorbing capacity of the Yield-Lok bolts, which could likely be increased significantly with adjustments to the anchor design. Product development work and testing is already underway to achieve this.

\section{A framework for dynamic simulations of excavations}

For engineers, the important question may be: How do we determine the dynamic capacity of an underground excavation and ground support system? The capacity of an excavation depends on many factors including:

- The excavation geometry.

- The rock mass conditions and structures in particular.

- The ground support system, comprising reinforcement, surface support and standing support.

- The failure criterion, which depends on many factors in a mining context and is not always clearly defined.

The demand also needs to be considered, and this depends on the excavation geometry, in situ stress field, mining sequence and the dynamic loading source.

In current practice, the dynamic capacity of an excavation is often characterised by a ppv limit (Potvin et al., 2010), which has several shortcomings arising from the simplified physical representation of the system. The ppv approach is still suitable for initial assessments during concept studies and for low risk excavations, but critical excavations like crusher chambers, shaft pillars, block cave extraction levels and transfer tunnels demand a more rigorous approach given the potential impact that failure can have on a mine. In the 21st century we have the capability to do more sophisticated analysis and this is likely to be a future path for designing critical excavations subject to dynamic loading.

Some aspects to consider for more rigorous simulations are discussed below. The simulations described in this paper utilised several elements of this framework but not all.

- Most rock mechanics problems are three dimensional and cannot be represented in two dimensions without applying considerable and usually unrealistic simplifications and assumptions. 3D simulations are therefore required in almost all cases.

- Structures need to be modelled explicitly. These are required to capture realistic deformation, which controls the response of the ground support system, and the localisation of rock mass damage associated with seismic events occurring on faults.

- Geometric complexity in the excavation geometry and geotechnical domains needs to be captured.

- The dynamic response of the ground support system needs to be well characterised and simulated as closely as possible. 
- The dynamic source needs to be considered carefully, since there are often several mechanisms that have a role in generating the dynamic loading conditions. Sources include natural and induced seismicity, blasting vibration and rapid deformation associated with, for example, pillar collapse as simulated here. A large amount of work has already been done on understanding and characterising these mechanisms (see, for example, outcomes of the Australian Centre for Geomechanics' project on Mine Seismicity and Rockburst Risk Management).

- The ray path between the source and the target will influence the dynamic loading of an excavation. This means that nearby excavations need to be included in the simulation. Additionally, the orientation of the excavation relative to the ray path can affect the dynamic response and resulting damage level.

- Different wave types, particularly at excavation surfaces, will affect the dynamic response. These should develop naturally with multi-scale 3D physics-based simulations.

- Attenuation effects need to be considered for far field sources. Attenuation arises from geometric spreading as stress waves propagate and so-called internal friction effects. Several mechanisms are responsible for internal friction but they can be lumped together in many cases.

- Material properties for rock, steel and fibrecrete all depend on the strain rate (Grady and Kipp, 1979), and so quasi-static properties measured in a laboratory are different to the properties realised at the high strain rates characteristic of dynamic loading. These dynamic properties need to be quantified to properly characterise the rock mass conditions and the ground support system for dynamic loading cases.

- Many excavations are surrounded by a pre-existing damage envelope, such as stress-induced fracturing, that arises from the quasi-static part of the excavation loading history associated with the excavation process itself, and from nearby excavations and mining activity. This damage envelope strongly affects the local rock mass conditions and the ground support system. The dynamic loads are superimposed upon these pre-existing conditions, and it is essential that they are considered in the simulation because they will strongly affect the dynamic response.

- The full dynamic loading history needs to be captured, since the duration of loading will certainly affect the response of the excavation and ground support system.

- The simulated frequency spectrum will be important since there are certain frequencies that are more likely to damage an excavation, just as low frequencies are the most damaging to surface structures during earthquakes. Spectral similitude should be the goal, at least for the frequencies that induce damage.

- The numerical method used for the simulation are irrelevant, but the simulation capabilities certainly are. As a minimum, the simulation software must capture:

- Complex interactions between structure, geometry and different material properties which necessitates 3D modelling.

- Realistic rock mass material model, indicating a requirement for a strain-softening dilatant constitutive formulation.

- The full dynamic behaviour with minimal numerical artefacts.

So, considering these aspects, the analysis can become complicated and poses several challenging research and development directions, although many important aspects are already demonstrated to some extent and realistic simulations are already possible with current technology (Beck et al., 2010; Campbell et al., 2011).

In our view, the design concept of capacity versus demand is limited in such complex situations because it implies that just a few numbers can specify the capacity or demand but of course the situation is usually 
more complicated, and simple explanations and analyses are not sufficient. The Columbia Accident Investigation Board (2003) described such situations thus:

It is our view that complex systems almost always fail in complex ways, and we believe it would be wrong to reduce the complexities and weaknesses associated with these systems to some simple explanation.

Given the known complexities in rock mechanics, this philosophy certainly applies when considering the dynamic behaviour of excavations and ground support systems. Indeed, this complexity is one reason why rockbursting remains such a significant risk for the mining industry globally. Many impressive advances have already been made in understanding the dynamic behaviour of individual ground support components, as summarised in the large body of literature on this topic including citations herein, but the key will be integrating these into a realistic and workable simulation framework to understand and quantify the behaviour of the entire excavation and ground support system together.

For engineers, the question then becomes: How do we determine a 'dynamic specification' for a critical excavation? This depends on the particular situation and many approaches could be used. One approach could be to assess the range of outcomes associated with a range of credible dynamic sources, such as rock mass damage, deformation and damage to the ground support system. The design engineer needs to decide if the forecast levels of damage and deformation are acceptable for the project, following risk management principles.

\section{Conclusions}

The simulation results presented in this paper show that Yield-Lok bolts can still retain load carrying capacity even with up to $1 \mathrm{~m}$ of closure, for the simulated dynamic loading conditions. For the same dynamic loading conditions, $\sim 30 \%$ of the fully encapsulated resin grouted rockbolts fail at $\sim 100 \mathrm{~mm}$ of closure. Although the integrity of the surface support system is usually the 'weak link' under high levels dynamic deformation, the yielding rockbolts therefore offer more capability for maintaining near-field excavation stability. The simulations reported here demonstrate several important components of a framework for realistic dynamic simulations of excavations and ground support systems. Several parts of this framework are proposed as technology development directions, and combining all parts into workable simulations will indeed be challenging, but for critical excavations, sophisticated analyses of this nature may be justified.

\section{Acknowledgement}

The authors gratefully acknowledge Jennmar Australia's permission to include the Yield-Lok testing data in this paper, and to use this data for developing the yielding bolt model simulated in this study.

\section{References}

Beck, D., Stacey, K. and Gilbert, D. (2010) Mine to tunnel scale discontinuum simulation of repeated dynamic loading of mine excavations, in Proceedings Second Australasian Ground Control in Mining Conference 2010, 23-24 November 2010, Sydney, Australia, The Australasian Institute of Mining and Metallurgy, Carlton.

Campbell A., Henley, K. and Lilley, C. (2011) Prevention of blast induced damage to underground mine infrastructure from open pit operations - A case study, in Proceedings Explo 2011, 8-9 November 2011, Melbourne, Australia, The Australasian Institute of Mining and Metallurgy, Carlton, pp. 161-174.

Columbia Accident Investigation Board Report Volume 1 (2003), NASA, Washington.

Dassault Systèmes (2013) Abaqus Analysis User's Manual, Dassault Systèmes SA, Vélizy-Villacoublay, viewed 2 April 2013 , http://www.3ds.com.

Grady, D.E. and Kipp, M.E. (1979) The micromechanics of impact and fracture of rock, International Journal of Rock Mechanics and Mining Sciences, Vol. 16, pp. 293-302.

Jennmar (2012) Yield-Lok bolt, Jennmar Australia, viewed 5 April 2013, http://www.jennmar.com/pdfs/JENNMAR_YieldLok.pdf.

Levkovitch, V., Reusch, F. and Beck, D. (2010) Application of a non-linear confinement sensitive constitutive model to mine scale simulations subject to varying levels of confining stress, in Proceedings Rock Mechanics in Civil and Environmental 
Engineering (EUROCK 2010), J. Zhao, V. Labiouse, J. Dudt and J. Mathier (eds), 15-18 June 2010, Lausanne, Switzerland, CRC Press, pp. 161-164.

Plouffe, M., Anderson, T. and Judge, K. (2008) Rock bolts testing under dynamic conditions at CANMET-MMSL, in Proceedings Sixth International Symposium on Ground Support in Mining and Civil Engineering Construction, 30 March-2 April 2008, Cape Town, South Africa, pp. 581-596.

Potvin Y., Wesseloo, J. and Heal, D. (2010) An interpretation of ground support capacity submitted to dynamic loading, in Proceedings Fifth International Seminar on Deep and High Stress Mining (Deep Mining 2010), M. Van Sint Jan and Y. Potvin (eds), 6-8 October 2010, Santiago, Chile, Australian Centre for Geomechanics, Perth, pp. 251-272.

Wu, Y.K. and Oldsen, J. (2010) Development of a new yielding rock bolt - Yield-Lok bolt, in Proceedings of 44th US Rock Mechanics Symposium and 5th US-Canada Rock Mechanics Symposium, 27-30 June 2010, Salt Lake City, USA, American Rock Mechanics Association, paper 10-197. 